\title{
Effect of Dominant versus Non-Dominant Unilateral Bag Carrying on Upper Trapezius Fatigue, Strength and Shoulder Function
}

\author{
DINA MAGDY, M.Sc.; WADIDA HASSAN, Ph.D. and MARY NASSIF, Ph.D. \\ The Department of Basic Science, Faculty of Physical Therapy, Cairo University, Giza, Egypt
}

\begin{abstract}
Background: In today's society, women have a lot of tasks at work, study, family, social events and this coupled with the use of large and heavy shoulder bags put them at a particular risk of injuries in the shoulder complex.

Aim of Study: This study aimed to compare between carrying a unilateral shoulder bag on the dominant versus non-dominant side on upper trapezius muscle fatigue, strength and shoulder function.

Subjects and Methods: One hundred and twenty healthy females right handed with age ranging from 20-59 were randomly assigned into 2 equal blocked groups. The outcome measures included, upper trapezius fatigue \& strength (via hand-held dynamometer) as well as shoulder function (via simple shoulder test). Both groups walked on a treadmill for 5 minutes with speed $1.1 \mathrm{~m} / \mathrm{s}$ (group A) was carried the bag on the dominant side \& (group B) was carried the bag on the non-dominant side. The outcome measures were collected pre $\&$ post-test for the dominant side (group A) \& the nondominant side (group B).
\end{abstract}

Results: The results of this study revealed that there were no significant differences in terms of fatigue \& function between pre $\&$ post measurments, but there was a significant difference in upper trapezius muscle strength for both groups. However, there were no significant differences between the dominant $\&$ non-dominant sides in terms of fatigue, strength $\&$ function.

Conclusion: Our results revealed that there were no significant differences when carrying a shoulder bag on the dominant $\&$ non-dominant side on upper trapezius fatigue, strength \& shoulder function.

Key Words: Healthy females - Upper trapezius fatigueStrength - Shoulder function.

\section{Introduction}

WOMEN are multi-taskers and hence need to carry many items to meet their needs \& house-held activities [1]. Women constantly need to carry heavy bags due to the multiple tasks they need to perform

Correspondence to: Dr. Dina Magdy Said Abd Elmomen, E-Mail:dinamagdy365@Hotmail.com or need to carry more physical activity-related items in their bag, which leads to pain experience [2]. The weight added by carrying a bag acts as an extrinsic load and affects many of the body's characteristics $[3,4]$. According to their weight, shape, carrying method, and location. Bags may induce abnormal postures and affect the musculoskeletal system, thereby leading to pain and spinal lesions [5].

The backpack weight of $20 \%$ body weight (BM) caused the most significant muscular and postural changes leading to fatigue [6]. The activity of the upper trapezius and erector spinae muscles become asymmetrical with increments in handbag weight [7]. Carrying backpacks recorded pain, swelling, fatigue and musculoskeletal discomfort in the upper or lower back, upper or lower trapezius, shoulders, neck and forearms [8,9]. Additionally, there was also an increased muscle activity of the trapezius muscle on the shoulder that the bag was worn on

The same-sided carrying led to excessive activity of the ipsilateral upper trapezius and contralateral erector spinae muscles. Carrying a shoulder bag with the same-sided, the load caused excessive postural isometric contraction of the upper trapezius [11].Tightness of the upper trapezius may compress the greater occipital nerve, which may lead to tension like a headache [12]. Such a load can also result in shoulder pain and may affect the cervical spine. Hence, the same-sided carrying and bag weight may have a significant correlation with shoulder pain [13].

However, the effect of single strapped bags on muscle activity present conflicting findings [14] It was found that there was increased contralateral muscle activity with an asymmetrical bag compared to symmetrical bag carriage [6]. Whereas no differ- 
ence in muscle activity between symmetrical and asymmetrical carriage was found, and asymmetric loading can increase energy expenditure which leads to rapid fatigue and cause progressive postural scoliosis $[\mathbf{1 5 , 1 6 ]}$

Hong (2008) investigated the effect of prolonged walking with a backpack on trapezius muscle activity and fatigue. Participants performed 20 min walking on the treadmill with different load $0 \%, 10 \%, 15 \%$, and $20 \%$ of BW. They found that with a $20 \%$ load, muscle fatigue occurred in the upper trapezius. With these findings, there was a need to investigate the effect of carrying a bag on the dominant versus non-dominant side on upper trapezius fatigue, strength and shoulder function [8]

\section{Subjects and Methods}

This study was conducted in the outpatient clinic of the Faculty of Physical Therapy, Cairo University, Egypt from 13 December 2020 to 3 January 2021. Based on a power analysis (G-power software 3.19.92), 120 healthy females were selected \& randomly assigned into equal blocked groups; dominant group (group A) \& non-dominant group (group B). This study had approval of the research ethical committee of Faculty of Physical Therapy, Cairo University, Egypt NO: P.T.REC/ 012/002946. Awritten informed consent were signed by 120 participants prior to the study. Inclusion criteria included; age range 17-29; BMI 18$25 \mathrm{Kg} / \mathrm{m}^{2}$; right dominant hand; didn't experience any neck pain 3months prior to the study; carrying bags around $10 \%$ of the BW. Participants were excluded if there were left dominant hand; experienced neck and shoulder pain within 3 months prior to the study prior to the study; participant doesnot carry there bags frontal or symmetrical; bag carriage of less than $5 \mathrm{~kg} \&$ athletes [17]

The primary outcome measure included strength that was obtained via calibrated hand-held dynamometer (HHD) (Lafayette Instrument Company, model 01163, USA). The HHD was calibrated before testing. While the participant was seated with arms by side, the dynamometer was placed halfway between the mastoid and lateral acromion over the muscle bulk. The examiner was allowed to use both hands and pressure was applied in a downward direction, and at the same time the participant was asked to shrug his shoulder $[18,19]$

Each participant was asked to keep a maximum voluntary contraction for 5 seconds, she repeated the contraction for three times with 30 seconds rest between each trial [20]. The average of the trials for each side was used for data analysis [21] Each participant from both groups was measured upper trapezius strength for both sides before walking on a treadmill (Sponeta, KS 11080801-1, SN: 2168B 1 OSD, Taiwan) without carrying the bag, then the measurement was taken another time after walking on the treadmill for $5 \mathrm{~min}$ with speeds $1.1 \mathrm{~m} / \mathrm{s}$ without any support on the treadmill sides while carrying the bag. The bag was $(33 \mathrm{~cm} \mathrm{X33 \textrm {cm }}$ $X 6 \mathrm{~cm}$ ) with a double strap, generally $2-4 \mathrm{~cm}$ wide and the bag weight was 5.5 to $7.5 \mathrm{~kg}(10 \%$ of $\mathrm{BW})$ [22].

Hand-held dynamometer has also been used to test upper trapezius fatigue. The same procedures mentioned before to measure muscle strength were carried out to measure upper trapezius fatigue by the maximum force static fatigue test. The participants were instructed to exert full effort to achieve maximal contraction during the static fatigue test. Standardized encouragement script such as squeeze hard repeatedly until the test ended was used. This was continued for 30 seconds, then to achieve fatigue the below equation was used to calculate static fatigue index (SFI) using the following equation:

$$
\text { SFI version } 2=100 \% \times\left(1 \frac{F_{\max 25-30 s}}{F_{\max 0-5 \mathrm{~s}}}\right)
$$

Static fatigue index (SFI), maximal force during the last $5 \mathrm{~s}\left(\mathrm{~F}_{\max } 25-30 \mathrm{~s}\right)$, maximal force in the first 5 seconds $\left(\mathrm{F}_{\max } 0-5 \mathrm{~s}\right)$.

Each participant from both groups was measured upper trapezius fatigue for both sides before walking on the treadmill without carrying the bag, and then walked on the treadmill while carrying the bag without any support on the treadmill for $5 \mathrm{~min}$ with speed $1.1 \mathrm{~m} / \mathrm{s}$. Repeated measurements of upper trapezius fatigue by HHD were carried out again while carrying the bag after walking on treadmill.

Simple shoulder test (SST) was then used to measure shoulder function limitation. It consists of 12 questions with dichotomous (yes/no) responses. The items of the SST are about function related pain ( 2 items), function/strength (7 items) and range of motion (ROM) (3 items). The total scores for SST range from 0 (worst or extreme limitations in physical function) to 12 (best or no physical limitation).

\section{Statistical analysis:}

Descriptive statistics were conducted for comparison of participant characteristics between groups. The shapiro-wilk test was conducted to test the normal distribution of data in both groups. 
The results revealed a significant deviation from the normal distribution in both groups accordingly nonparametric analysis was carried out. Wilcoxon signed ranks was conducted for comparison between pre and post-carrying in both groups and mann-whitney U test was conducted for comparison between groups. The level of significance for all statistical tests was set at $p<0.05$. All statistical analysis in both groups was conducted through the statistical package for social studies (SPSS) version 25 for windows (IBM SPSS, Chicago, IL, USA).

\section{Results}

Table (1) showed the participants characteristics of the dominant group (group A) and the nondominant group (group B). There was no significant difference between groups in age, gender, weigth, heigth \& BMI distribution $(p>0.05)$.

There was no significant difference in upper trapezius fatigue post carrying compared with that pre carrying in both groups $(p>0.05)$. While there was a significant decrease in upper trapezius strength post carrying compared with that pre carrying in both groups $(p<0.05)$ (Table 2$)$.

There was no significant difference between groups in all variables pre-carrying $(p>0.05)$. Comparison between the groups post carrying revealed non-significant differences in upper trapezius fatigue, strength and SST between groups $(p>0.05)$ (Table 2).

Table (1) Basic characteristics of participants.

\begin{tabular}{llll}
\hline & $\begin{array}{c}\text { Group A } \\
\text { Mean } \pm \text { SD }\end{array}$ & $\begin{array}{c}\text { Group B } \\
\text { Mean } \pm \text { SD }\end{array}$ & $\begin{array}{c}p- \\
\text { value }\end{array}$ \\
\hline Age (years) & $35.3 \pm 8.63$ & $36.8 \pm 8.23$ & 0.33 \\
Weight $(\mathrm{kg})$ & $60.61 \pm 9.33$ & $63.51 \pm 10.46$ & 0.11 \\
Height $(\mathrm{cm})$ & $160.55 \pm 6$ & $162.06 \pm 7.53$ & 0.22 \\
BMI $\left(\mathrm{kg} / \mathrm{m}^{2}\right)$ & $23.48 \pm 3.09$ & $24.21 \pm 3.8$ & 0.25 \\
\hline
\end{tabular}

SD: Standard deviation. $\quad p$-value: Level of significance.

Table (2): Median values of upper trapezius fatigue and strength pre and post carrying and SST of group $\mathrm{A}$ and $\mathrm{B}$.

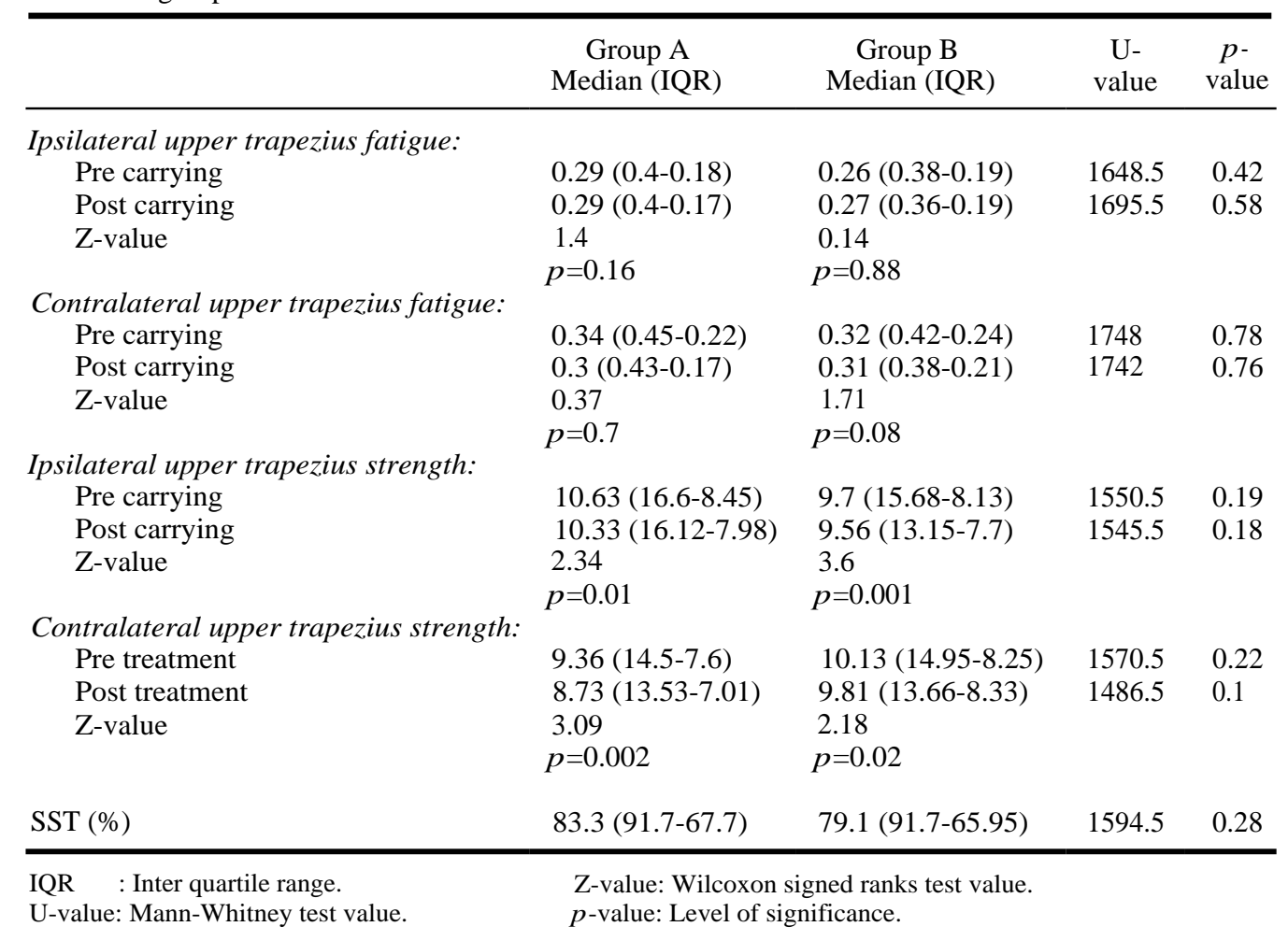

\section{Discussion}

The aim of our study was to compare between carrying a unilateral shoulder bag on the dominant versus the non-dominant side on upper trapezius muscle strength, fatigue and shoulder function. Results of the study found that there were no significant differences in terms of fatigue \& function between pre \& post measurments, but there was a significant difference in upper trapezius muscle strength for both groups. However, there were no significant differences between dominant $\&$ non-dominant sides in terms of strength, fatigue $\&$ function. 
Our results come in line with Hong (2008) where they found that carrying a bag with $10 \%$ BW had no significant effect on muscle activity and fatigue of trapezius [8]. Furthermore, Rodrigues et al. (2020) found that regardless of the side used to carry the bag and the weight of the bag while carrying shoulder bags, the changes perceived during gait were discrete [23]. Additionaly, Son (2013) found that the differences in spatial and temporal gait variables were not exhibited when the bag was carried using the four methods (on the left shoulder, on the left hand, on the right shoulder and on the right hand) [24]. Also, An et al. (2010) found that between various methods of carrying preferred to korean young women the "over-theshoulder" method has the least effect on gait parameters relative to not carrying a bag [25]

This would be implicated by the fact that the trapezius muscle activations in the EMG analysis was affected by carrying methods mainly when participants were carrying around $15 \%$ of their BW [26]. Knott et al. [27] mentioned that with 15\% and $20 \%$ weight on either side of the body, the sagittal imbalance, coronal imbalance, shoulder tilt and weight distribution all shifted significantly from the neutral position.

Our finding comes in contradicting with $\mathrm{Ab}$ utaleb (2016), whom measured the dynamic postural stability in three different situations (without carrying a shoulder side pack, with carrying a shoulder side pack on the dominant side, and on the non-dominant side) with a rest period in between. They found that postural stability wasn't disturbed during carrying a shoulder side pack on the non-dominant side when compared to carrying it on the dominant side [28]

Thus, the individual who continuously uses one-sided carrying technique may be prone to fatigue due to increased muscular activity on the side opposite to the load. In addition, increased muscular activity may lead to greater compressive forces on spinal structures [29]. Bag carrying methods didn't affect the gait variables, but only bagcarrying habits had significant effects on gaits. Therefore, it may be necessary for people to be aware of the negative effects on posture caused by their bag-carrying habits.

Conclusion: It can be concluded that there is no difference between carrying a shoulder bag on the dominant and non-dominant side on upper trapezius strength, fatigue and shoulder function.
Limitation of the study: This is study is limited to carrying bags weight equal to $10 \%$ of the body weight.

Future studies are needed to investigate the effect of carrying heavier shoulder bags for longer duration and in different patterns.

\section{Acknowledgments:}

The authors thank all individuals participated in this study.

\section{Authors' Contribution:}

All authors contributed equally to the whole research processes as conceptualization, data curation, investigation, methodology, project administration, resources, writing-review, editing, approved the final version of the manuscript, and agree with the order of presentation of the authors.

\section{Funding/Support:}

The authors received no financial support for the research and publication of this article.

\section{Declaration of interest:}

The authors declare that there is no conflict of interest that could be perceived as prejudicing the impartiality of the research reported.

\section{References}

1- TRISTANE R.C. and ROIM T.P.: The history of the stock market: its evolution in the historical context of women's fashion. Revista Cientifica de Ciencias Aplicadas da FAIP, 2: $1-9,2015$.

2- ABDON A.P., MORAES T.E., SALES M.P., et al.: Relationship between shoulder pain and weight of shoulder bags in young women, 14: 40-47, 2018.

3- PALUMBO N., GEORGE B., JOHNSON A. and CADE D.: The effects of backpack load carrying on dynamic balance as measured by limits of stability. Work, 16: 123129, 2001.

4- CHOW D.H., KWOK M.L., CHENG J.C., et al.: The effect of backpack weight on the standing posture and balance of schoolgirls with adolescent idiopathic scoliosis and normal controls. Gait Posture, 24 (2): 173-181, 2006.

5- GRIMMER K., DANSIE B., MILANESE S., PIRUNSAN U. and TROTT P.: Adolescent standing postural response to backpack loads: A randomised controlled experimental study. BMC Musculoskeletal Disorders, 3: 74-84, 2002.

6- PISCIONE J. and GARNET D.: Effect of mechanical compression due to load carrying on shoulder muscle fatigue during sustained isometric arm abduction: An electromyographic study. European Journal of Applied Physiology, 6: 221-228, 2006.

7- PHONPICHIT C., CHANSIRINUKOR W. and AKAMANON C.: The response of the body when carrying a handbag. Work, 55 (3): 673-678, 2016. 
8- HONG Y., LI J.X. and FONG D.T.: Effect of prolonged walking with backpack loads on trunk muscle activity and fatigue in children. Journal of Electromyography and Kinesiology, 18: 990-996, 2008.

9- LASOTA A.: Schoolbag weight carriage by primary school pupils. Work, 48: 21-26, 2014.

10- HARDIE R., HASKEW R., HARRIS J. and HUGHES G.: The effect of bag style on muscle activity of the trapezius, erector spinae and latissimus dorsi during walking in female university students. Journal of Human Kinetics, 45: 39-47, 2015.

11- MUSCOLINO J.E.: Know the body: Muscle, bone, and palpation essentials. St Louis, Mosby, 2011.

12- KISNER C. and COLBY L.A.: Therapeutic exercise: Foundations and techniques. 6 th ed. Philadelphia, FA Davis, 2012.

13- CHO S.H., LEE J.H. and KIM C.Y.: The Changes of Electromyography in the Upper Trapezius and Supraspinatus of Women College Students According to the Method of Bag-carrying and Weight. Journal of Physical Therapy Science, 25: 1129-1131, 2013.

14- QURESHI Y. and SHAMUS E.: Unilateral shoulder bags: Can they be worn in a way to reduce postural asymmetry? Internet Journal of Allied Health Science and Practice, 10: 23-31, 2012.

15- SMITH B., ASHTON K.M., BOHl D., et al.: Influence of carrying a backpack on pelvic tilt, rotation, and obliquity in female college students. Gait Posture, 23 (3): 263-267, 2006.

16- SAHRMANN S.A.: Movement system impairment syndromes of the extremities, cervical and thoracic spines. St Louis, Elsevier, 2011.

17- RODRIGUES B.K., MACIEL M.A. and PARENTE BL.: Use and weight of shoulder bag in female gait. Motricidade, 16: 144-155, 2020.

18-RASOULI A., JAMSHIDI A. and SOHANI S.: Comparing the Isometric Strength of the Shoulder and Scapulothoracic Muscles in Volleyball and Futsal Athletes. Physical Treatments, 7 (1): 41-48, 2017.
19- TURNER N., FERGUSON K., MOBLEY B.W., RIEMANN B. and DAVIES G.: Establishing normative data on scapulothoracic musculature using handheld dynamometry. Journal of Sport Rehabilitation. Human Kinetics, 18 (4): 502-20, 2009.

20- SHANNON M. and SARAH N.: Lower Trapezius Muscle Strength in Individuals With Unilateral Neck Pain. journal of Orthopaedic \& Sports Physical Therapy, 2011.

21- SEVERIJNS D., LAMERS I., KERKHOFS L. and FEYS P.: Hand grip fatigability in persons with multiple sclerosis according to hand dominance and disease progression. Journal of Rehabilitation Medicine, 47 (2): 154-160, 2015.

22- CHOW D.H., HIN C.K. and LAI A.: Carry-over effects of backpack carriage on trunk posture and repositioning ability. International Journal of Industrial Ergonomics, 41: 530-535, 2011.

23- RODRIGUES B.K., MACIEL M.A. and PARENTE B.L.: Use and weight of shoulder bag in female gait. Motricidade, 16: 144-155, 2020.

24- SON S.M. and NOH H.: Gait Changes Caused by the Habits and Methods of Carrying a Handbag. Journal of physical therapy science, 25: 969-971, 2013.

25- AN D.H., YOON J.Y. and YOO W.G.: Comparisons of the gait parameters of young Korean women carrying a single-strap bag. Nursing and Health Sciences, 12: $87-$ 93, 2010.

26- ABARAOGU U.O., UGWA W.O., ONWUKA E. and ORJI E.: Effect of single and double backpack strap loading on gait and perceived exertion of young adults. Journal of Back and Musculoskeletal Rehabilitation, 29: 109-115, 2016.

27- KNOTT P., DAVIS S., HARRISON A. and LARSON C. The effect of a unilateral upper extremity load (backpack) on the resulting spinal posture. Scoliosis, 8: 8-11, 2013.

28- ABUTALEB E.E.: Effect of shoulder side pack on dynamic postural stability in young healthy female. International Journal of Physiotherapy, 3: 252-257, 2016.

29- COOK T.C. and NEUMANN D.A.: The effects of load placement on the EMG activity of the low back muscles during load carrying by men and women. Ergonomics, 30: 23-1413, 1987. 


\section{تأثير حمل حقائب الكتف على جهة واحدة على الجهل الجانب السائد

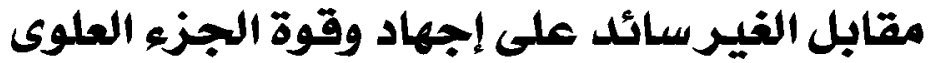

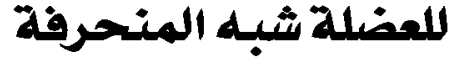

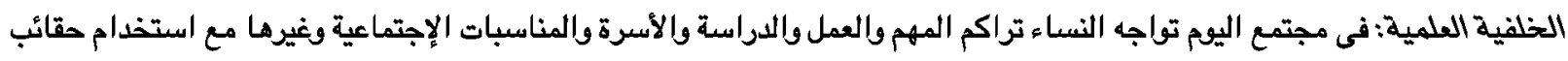

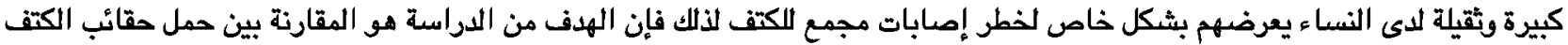
الماحد على الجانب السائد مقابل الجانب الفير سعائد على إجهاد وققة الجزء العلوى اللعضلة شبه المنحرفة.

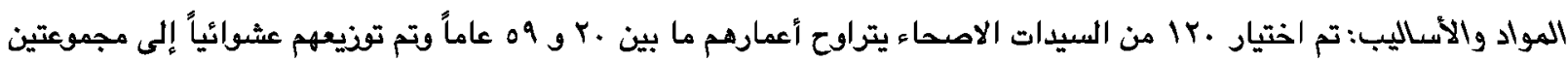

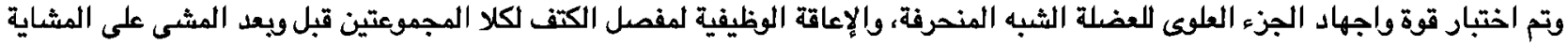

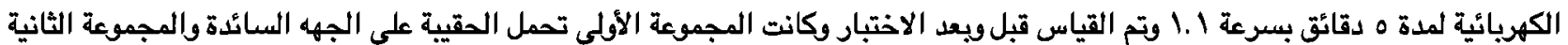

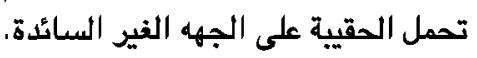

النتائج: النتائج الدراسة عكست عدم وجود فرق في كل القياسات قبل ويعد القياس لكلا المجموعتين ولم يكن هناك فرق بين الجهه السائدة

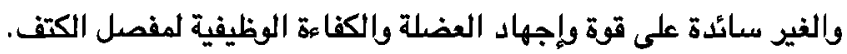

الخلاصة: على حسب نتائجنا والتى عكست عدم وجود فق بين حمل الصقائب على الجهه السائدة والغير السـائدة على قوة وإجهاد الجزء

العلوى اللعضلة شبه المنحرفه والكفاءة الوظيفية. 